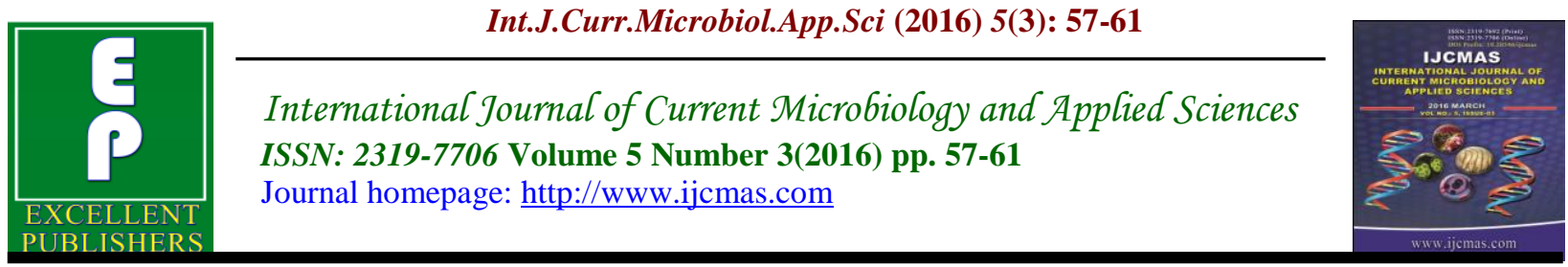

Case Study

http://dx.doi.org/10.20546/ijcmas.2016.503.008

\title{
Isolation of Aeromonas salmonicida from Human Blood Sample: A Case Report
}

\author{
Archana Bora $^{1}$ *, K. L. Seervi ${ }^{1}$, P.K.Khatri ${ }^{1}$, Aruna Solanki ${ }^{1}$, Arvind Kishore Chandora ${ }^{1}$, \\ Saroj Meena $^{2}$, Ajay Chandora ${ }^{2}$, Laxmi Rathore ${ }^{2}$ and Manju Daila ${ }^{2}$ \\ Department of Microbiology, Dr. S.N. Medical College, Shastri Nagar, \\ Jodhpur (342003), Rajasthan, India \\ *Corresponding author
}

\begin{abstract}
A B S T R A C T
Keywords

Aeromanas

salmonicida,

Septicemia,

Fish

Article Info

Accepted:

07 February 2016

Available Online:

10, March 2016

Aeromanas salmonicida belonging to the genus Aeromonas is a common pathogen that causes furunculosis and septicemia in variety of fishes. It infects cold blooded vertebrates living at low temperature mainly salmonid fish hence named salmonicida. Aeromanas salmonicida is considered to be a fish pathogen, non-pathogenic for humans as it cannot grow at $37^{\circ} \mathrm{C}$. However, In our laboratory culture plates, blood culture bottle and broths were incubated twice at $37^{\circ} \mathrm{C}$ and each time same type of colonies were isolated which were identified as A. samonicida by Vitek 2 compact automated system. By far one case has been reported regarding its isolation from human biological sample. Here we present the second case report of $A$. salmonicida isolated from the human blood.
\end{abstract}

\section{Introduction}

Aeromanas salmonicida belonging to the genus Aeromonas is a common pathogen that causes furunculosis and septicemia in variety of fishes. It infects cold blooded vertebrates living at low temperature mainly salmonid fish hence named salmonicida. Aeromanas salmonicida is considered to be a fish pathogen, non-pathogenic for humans as it cannot grow at $37^{\circ} \mathrm{C}$.

By our best knowledge, till date Tewari et $a l$., study has been reported first case of
Aeromanas salmonicida from human blood (Tewari et al., 2014).

\section{Case Report}

A 12-year-old Muslim female child, visited medicine Out Patient Department (OPD), at AIIMS, Jodhpur in December 2015 with complaints of off and on low grade fever, pain abdomen associated with weakness and malaise for last 20 days. There was no history of chills and rigor, sore throat, diarrhea, urinary discomfort, any other 
localized infection, or chronic illness suggestive of immune compromised state except history of RHD for which she is taking medicines regularly. There is history of fish ingestion from local pond, few days before symptoms arise. All the routine investigations were found to be normal except leucocytes which were slightly raised.

Blood sample was sent to our Department of Microbiology, Dr. S. N. Medical College, Jodhpur lab for culture and sensitivity. After overnight incubation, turbidity and haemolysis were reported in blood culture bottle. Blood culture broth was sub cultured on blood agar plate and MacConkey agar plate and incubated overnight. Next day, pinpoint yellowish colonies, friable, not easily emulsifiable and non-hemolytic and having entire margin grew on blood agar plate. (figure-1) No growth was observed on MacConkey Agar. On Gram's staining, gram negative bacilli with no specific arrangement were seen. (figure-2) The organism was nonmotile, catalase positive and oxidase positive. Triple sugar iron (TSI) was $\mathrm{K} / \mathrm{K}$, hydrogen sulphide production negative, indole negative, urease negative and citrate utilization test negative. (Baron $\mathbf{J}$ and Finglod S., 1996) As identification could not be clearly made by these biochemical test hence blood agar plate was re-incubated. Next day, colour of colonies turned golden yellow where as size of colonies became larger.

As identification of organism could not be done by conventional biochemical reactions second sample was collected on her second visit. Sample was processed by BacT alert (BioMeriux, New York) and sub cultured on Blood and MacConkey agar and incubated overnight at $37^{\circ} \mathrm{C}$. Next day colonies with same morphology (as of first sample) were isolated. For second sample identification was done and confirmed by Vitek 2 compact system. To our surprise report showed isolation of Aeromanas salmonicida.

Antibiotic sensitivity was determined by Kirby Bauer's disk diffusion method as per CLSI guidelines. The isolate was found to be sensitive to drugs (disks of Himedia) Imipenem (10 mcg), Ceftazidime (30 mcg), Ceftriaxone (30 mcg), Levofloxacin (5 $\mathrm{mcg}$ ), and Amikacin (30 mcg) while resistant toAmpicillin (10 $\mathrm{mcg})$ \&Tetracycline (30 mcg).

\section{Results and Discussion}

Member of the genus Aeromonas have been recognized since 1891, when Sanerelli, first reported them in frog and produced septicemia and other diseases upon reinoculation into cold and warm blooded animals. Through the use of improved techniques for isolation and identification from biological specimens their importance in human has recently become better appreciated. Much advancement has occurred regarding their taxonomy, disease spectrum and pathogenicity over many past years. (J.M. Janda, S. Duffey, 1988)

Aeromanas salmonicida belonging to the genus Aeromonas, was first discovered in a Bavarian brown trout hatchery by Emmerich and Weibel in 1894. (Amos, k., 2013) It is facultative anaerobe, Gram negative, non motile bacterium which readily ferments and oxidizes glucose and give catalase and oxidase test positive. (Kim et al., 2011) It is considered as primary pathogen in variety of fishes (Kim et al., 2011; Ishiguro et al., 1981) and not in humans as they cannot grow at $37^{\circ} \mathrm{C}$. Optimal temperature required for its growth has been reported as $22-25^{\circ} \mathrm{C}$. (Austin, 1986) In 90\% of the strains, its virulence was found to be lost if cultured at $30^{\circ} \mathrm{C}$ and above. (Ishiguro et al., 1981) 
Previously other Aeromonas species like A. hydrophila, A. caviae, A. veronii etc. were also considered as pathogen in cold blooded animals only, including fish, amphibians and reptiles but gradually recognized as opportunistic pathogen for human. However these organisms have increasingly been identified as a primary pathogen for humans in normal individual as well as in immunecompromised patient mainly in gastrointestinal infections and septicemias. (Kao et al., 2003) Major sources described for Aeromonas species in gastrointestinal infection are environment-water-animal complex and ingestion of contaminated foods whereas sources reported for extraintestinal infection are either direct soil or water contact or ingestion of contaminated food followed by bacterimic dissemination from gastro intestinal tract. (Abott, 1998)

Figure.1 Aeromanas salmonicida colony on Blood Agar

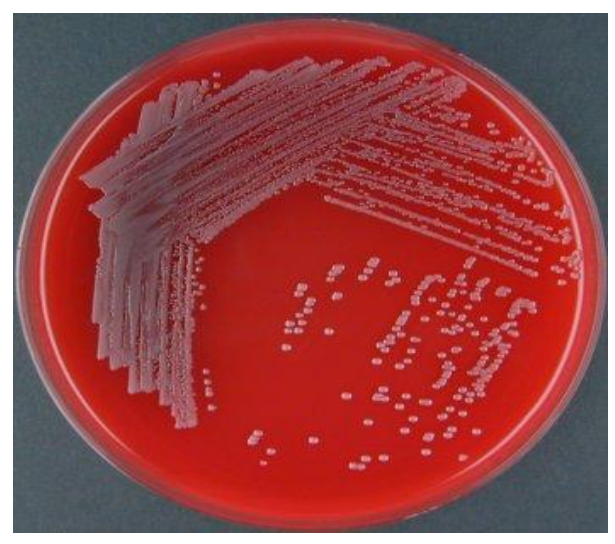

Figure.2 Aeromanas salmonicida seen on Gram's Stain

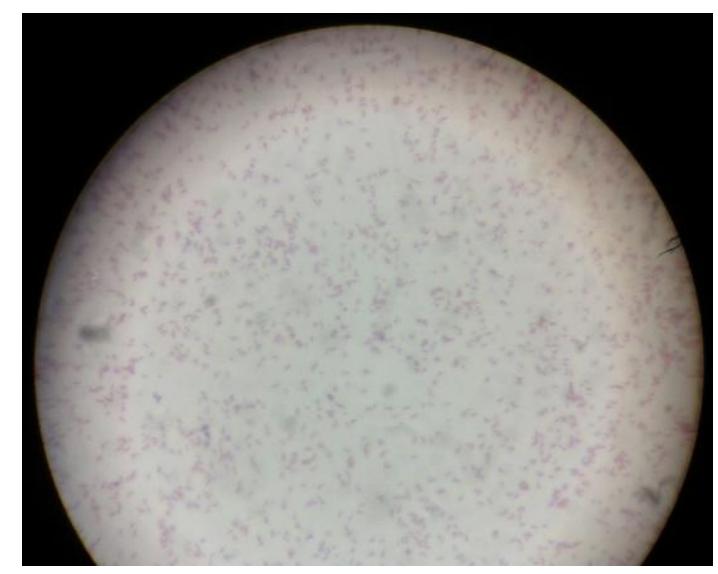


Figure.3 Biochemical Reaction Pattern of Isolate

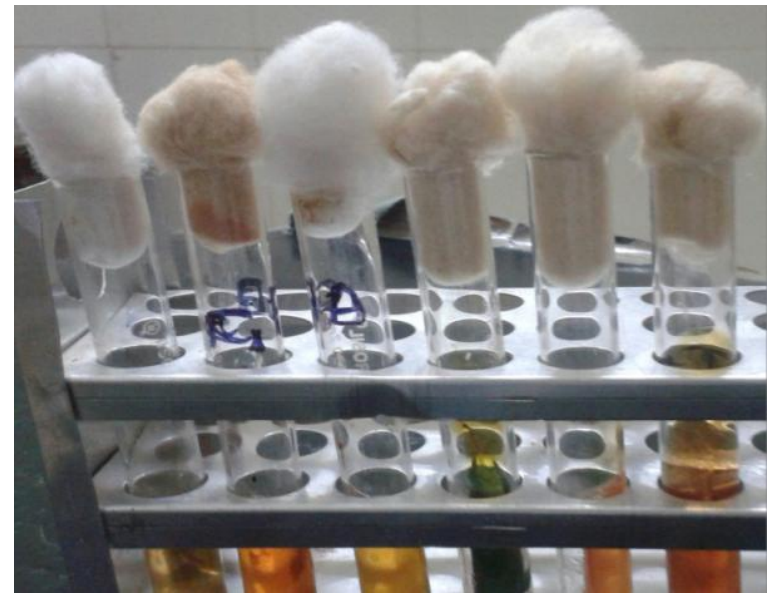

Figure.4 Antimicrobial Susceptibility Test of Isolate

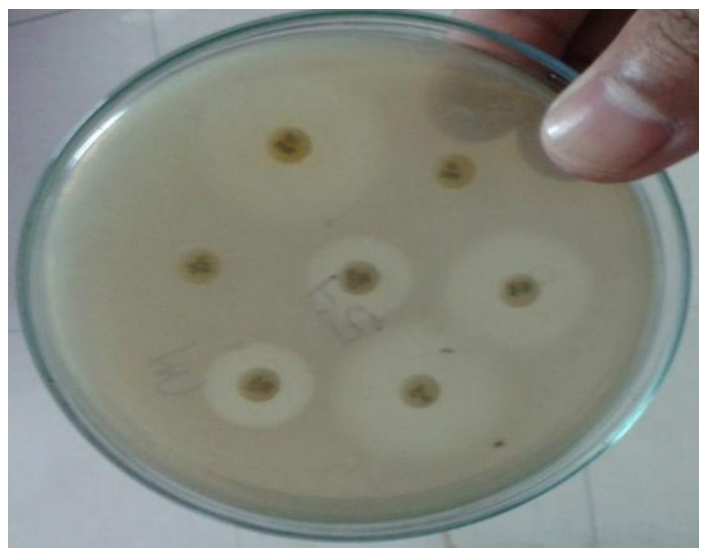

Compared with other pathogenic Aeromonas A. salmonicida can also be found in environment, diseased fish and water and may be transmitted by all these sources. Also it has pathogenic factor S- layer which mediates tissue adherence as in other Aeromonas like A. hydrophila, A. veronii so it may also act as pathogen in humans like other species. (Ishiguro et al., 1981; Igbinosa et al., 2012) Although previously documented that growth is unlikely at $37^{\circ} \mathrm{C}$ and so in humans (Ishiguro et al., 1981) which is contradictory to our report where blood samples were cultured by two different methods (conventional and BacT alert) and sub-cultured plates were incubated at $37^{\circ} \mathrm{C}$ and for both samples (first and second) same colonies were isolated which suggests that either $A$. salmonicida has undergone some changes and can grow at $37^{\circ} \mathrm{C}$ or it has been misidentified by Vitek 2 system.

We have limited resources and facilities to work on molecular basis in our setup hence this Vitek 2 report could not be confirmed further but we can throw the light on this organism and make the scientists to rethink and work more on this organism to find any change undergone by this organism in pathogenicity, virulence, disease spectrumand antibiotic resistance.

Our isolate was found sensitive to drugs 
(disks of Himedia) Imipenem (10 mcg), Ceftazidime $(30 \mathrm{mcg})$, Ceftriaxone $(30$ mcg), Levofloxacin (5 mcg), and Amikacin $(30 \mathrm{mcg})$ while resistant toAmpicillin (10 $\mathrm{mcg}) \&$ Tetracycline $(30 \mathrm{mcg})$.Isolate found in Tewari et al., study was sensitive to all drugs (by Kirby Bauer's method) Recently antibiotic resistant $A$. salmonicida strains have been recognized as a serious concern owing to their potential health risk to humans and animals (Amos, 2013). Has this problem been evolved by humans only who are devising techniques and facilities to cross all the boundaries and getting interacted with all types of living and non living things?

To conclude, society is already overburdened with resistant organism and if nonpathogenic organisms will change their host preference, virulence and sensitivity, it will be difficult for clinicians and scientists to tackle this problem.

\section{References}

Abott, S.L., Seli, S.L. 1998. Misidentification of Unusual Aeromonas Species as members of the Genus Vibrio: a continuing problem. J. Clin. Microbiol., 364: 1103-8.

Amos, K. 2013. Disease interactions of wild and cultivated salmon. 2011 Available http://www.psmfc.org/ans_presentations/A mos K.pdf Accessed on 14 August 2013.

Austin, B., Bishop, I., Gray, C., Watt, B., Dawes, J. 1986. Monoclonal antibodybased enzyme-linked immune absorbent assay for the rapid diagnosis of clinical cases of enteric red mouth and furunculosis in fish farms. J. Fish Dis., 9: 469-74.

Baron, J., Finglod, S. 1996. Methods for identification of etiologic agents of infectious Diseases. Baily \& Scott's diagnostic microbiology. 10th ed. St. Louis, USA: Mosby, Inc; 1996. pp.327529.

Igbinosa, I.H., Igumbor, E.U., Aghdasi, F., Tom, M., Okoh, A.I. 2012. Emerging Aeromonas Species Infections and Their Significance in Public Health. Scien. World J., 625023

Ishiguro, E.E., Kay, W.W., Ainsworth, T., Chamberlain, J.B., Austen, R.A., Buckley, J.T. 1981. Loss of virulence during culture of Aeromanas salmonicida at high temperature. J. Bact., 1481: 333-40.

Janda, J.M., Duffey, S. 1988. Mesophilic aeromonads in human disease: current taxonomy, laboratory identification and infectious disease spectrum. Rev. Inf. Dis., 10-980.

Kao, H.T., Huang, Y.C., Lin, T.Y. 2003. Fatal bacteremia pneumonia caused by Aeromonas hydrophila in a previously healthy child. J. Microbiol. Immunol. Infect., 36: 209-211.

Kim, J.H., Hwang, Y.S., Son, J.S. 2011. Molecular characterization of tetracycline and quinolone resistant Aeromanas salmonicida isolated in Korea. J. Vet. Sci., 121: 41-48.

17th Edition. Vol. 27. Clinical and Laboratory Standards Institute, Wayne; 2007. Performance Standards for Antimicrobial Susceptibility Testing; 17th informational supplement, Clinical and Laboratory Standards Institute CLSI) M100-S17: p. 3.

\section{How to cite this article:}

Archana Bora, Seervi, K. L., Khatri, P.K., Aruna Solanki, Arvind Kishore Chandora, Saroj Meena, Ajay Chandora, Laxmi Rathore and Manju Daila. 2016. Isolation of Aeromonas salmonicida from Human Blood Sample: A Case Report. Int.J.Curr.Microbiol.App.Sci. 5(3): 57-61. doi: http://dx.doi.org/10.20546/ijcmas.2016.503.008 